\title{
On the LiDAR contribution for landscape archaeology and palaeoenvironmental studies: the case study of Bosco dell'Incoronata (Southern Italy)
}

\author{
R. Coluzzi, A. Lanorte, and R. Lasaponara \\ Istituto di Metodologie per l'Analisi Ambientale, IMAA-CNR, C. da S.Loja - 85050 Tito Scalo (PZ), Italy
}

Received: 22 January 2010 - Revised: 25 February 2010 - Accepted: 3 March 2010 - Published: 1 June 2010

\begin{abstract}
This paper focuses on the potential of the latest generation of Airborne laser scanning (ALS) for the detection and the spatial characterization of microtopographic relief linked to ancient landscapes and palaeoenvironmental features. ALS is an optical measurement technique for obtaining high-precision information about the Earth's surface including basic terrain mapping (Digital terrain model, bathymetry, corridor mapping), vegetation cover (forest assessment and inventory), coastal, and urban areas. Recent studies examined the possibility of using ALS in archaeological investigations to identify earthworks, although the ability of ALS measurements in this context has not yet been studied in detail.

In this study, the investigations based on ALS survey and aerial photos were carried out for the natural protected area, Bosco dell'Incoronata in the Apulia Region (Southern Italy). The investigated area is an important site from the naturalistic, historic and archaeological point of view. It is an ancient lowland forest, still present in the medieval time, which has been characterized by a long and intensive human activity from Neolithic to Middle Ages. The LiDAR based analysis allowed us to identify features not visible from ground or from optical data set because hidden by forest canopy and dense understory. The DTM enabled us to identify some microtopographic relief linked to traces of past landscapes, as in the case of the Cervaro paleaoriverbed. It is quite interesting to note that the river changed many times from North to South side compared to the present stream, and traces of past human activities can be still evident close to the diverse paleaoriverbeds. Nevertheless, intensive and systematic study of the ancient landscapes of the Bosco dell'Incoronata is just beginning and so far questions tend to be raised rather than answered.
\end{abstract}

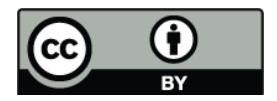

Correspondence to: R. Lasaponara (lasaponara@imaa.cnr.it)
The current study emphasizes the potential of aerial LiDAR (Light Detection And Ranging) survey for detecting surface discontinuities and microtopographic relief linked to palaeoenvironmental features, even hidden by under dense canopy and understory.

\section{Introduction}

Space and airborne remote sensing based on active and passive sensors can be fruitfully used for archaeological and paleaoenvironmetal studies to search larger areas, to obtain accurate quantitative information on ancient landscape and to detect archaeological features in a more rapid manner compared to traditional survey techniques (Lasaponara and Masini, 2005, 2006, 2008; Giardino, 2008).

In particular, the advent of LiDAR technologies generally known as ALS has completely revolutionized the area of topographic surveying and offers new data sources for a variety of promising applications, among them landscape studies and archaeological investigations (Lasaponara et al., 2009; Lasaponara et al., 2010) to depict micro-topographic earthworks in vegetated and non-vegetated areas.

ALS (Airborne Laser Scanning) is an active remote sensing technology, based on laser pulses, which measures properties of scattered light to find range and/or other information of a distant target. The range to an object is determined by measuring the time delay between transmission of a pulse and detection of the reflected signal.

ALS can be mounted onboard an airplane or helicopter. The acquisition system consists of the following individual components: (i) laser ranging device, (ii) Inertial Measuring Unit (IMU), (iii) onboard Global Positioning System (GPS) positioning device, (iv) ground GPS data acquisition at the same time as the LiDAR survey, (v) Digital Camera (Optional). While each of these components are operating independently, the integration of all of them that allows us

Published by Copernicus Publications on behalf of the European Geosciences Union. 
to obtain measurements with a high level of accuracy. The LiDAR technology exceeds other methods such as stereophotogrammetry or interferometric SAR particularly in vegetated areas due to the direct determination of elevation and the penetration capabilities of the laser beam through gaps in vegetation.

Through its efficient data sampling capabilities ALS has completely revolutionized the area of bathymetric and topographic surveying, corridor mapping and coastal and urban area monitoring. ALS data are used in land cover classification, to estimate forest tree height, to assess seasonal canopy differences, to obtain forest inventories. The applications of ALS have been increasing rapidly over recent years. Recent studies have examined the possibility of using LIDAR in the management of archaeological monuments (Barnes, 2003), landscape studies and archaeological investigations to depict micro-topographic earthworks in non-forested (Shell and Roughley 2004; Challis 2006; Corns and Shaw 2008) and forested areas (Devereux et al., 2005; Crutchley 2008; Doneus et al., 2008).

The latest generation of ALS, now available, is the FullWaveform (FW) scanner which offers improved capabilities especially in areas with complex morphology and/or dense vegetation cover. Nowadays investigations based on the latest generation of ALS are still quite rare, the majority of published studies are based on data collected by conventional ALS.

In this paper we present the results obtained from the analysis of FW-ASL survey for the natural protected area, Bosco dell'Incoronata in the Apulia Region (Southern Italy). It is an ancient lowland forest, still present in the medieval time, which has been characterized by a long and intensive human activity from Neolithic to Middle Ages. The LiDAR based analysis allowed us to identify features linked to ancient landscapes not visible from ground or from aerial photos because hidden by dense forest canopy and understory.

\section{LiDAR data processing}

\subsection{DTM extraction}

The workflow for processing airborne laser data (LiDAR) and airborne images may be divided into five major steps: (i) initial setup and data calibration, (ii) classifying points, (iii) processing images, (iv) validating positioning, and (v) creating delivery products.

The initial setup involves importing all the necessary raw data into the processing software, applying coordinate transformations and calibration, which is based on the comparison of the laser data produced by different flight passes which overlap each other.

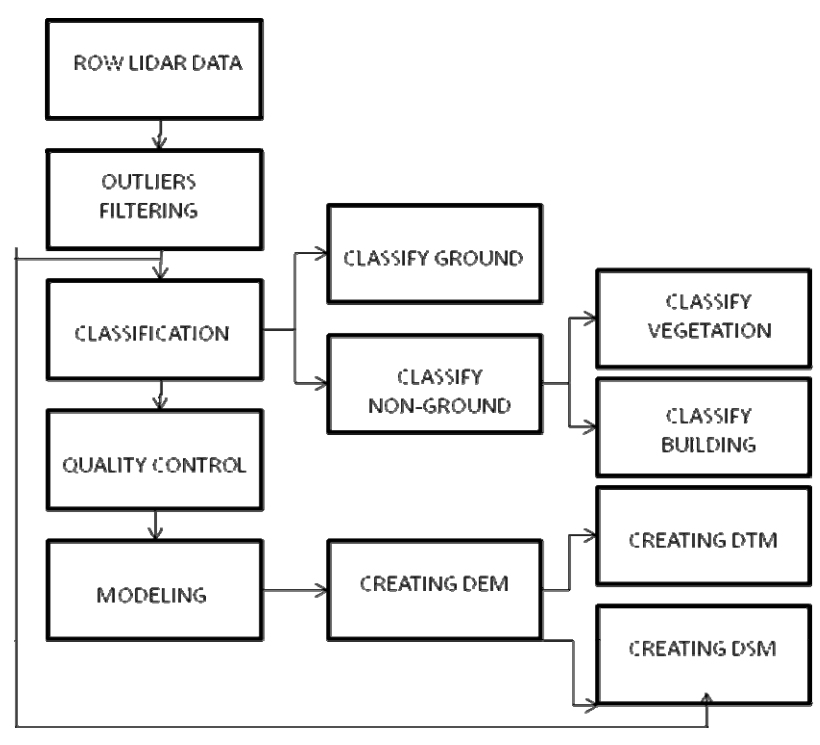

Fig. 1. Workflow for DSM and DTM extraction.

Later both Digital Surface Model (DSMs) and Digital Terrain Model (DTMs) are obtained. For archaeological investigation, a high quality digital terrain model (DTM) has to be derived from the ALS data. This demands a detailed and reliable separation of on-terrain and off-terrain points while maintaining a high point density. The separation of terrain and off-terrain points is generally called classification, and can be obtained using the diverse laser measurements and information, such as: (i) height; (ii) intensity; (iii) echo width. Herein, we will focus on the elaboration performed using both height, obtained from the 3-D point clouds, and orthophoto acquired at the same time as ALS survey.

Due to its efficient data sampling capabilities, FW-LIDAR is capable of detecting microtopographic relief with an altimetrical resolution around $0.1 \mathrm{~m}$. To achieve this level of resolution, it is necessary to process the ALS point cloud using appropriate numerical filters. For this case study, we used the Gaussian Pulse Estimation (Shie Qian and Dapang Chen, 1996) algorithm implemented in the commercial software Terra Scan (Terrasolid, www.terrasolid.fi).

TerraScan classification is based on a parametric approach and develops according to an orderly sequence of stages decided by an operator (see Fig. 1). In this case study, the classification of laser data was performed using a strategy based on a set of "filtrations of the filtrate". Appropriate criteria for the classification and filtering were set to gradually refine the intermediate results. The data classification process starts by including all the point cloud in to a single class, called the default class, which becomes the reference for the next processing. The elimination of outliers points is performed through two classification algorithms: (i) "low point" and (ii) "isolated points". The first finds single points or groups of 


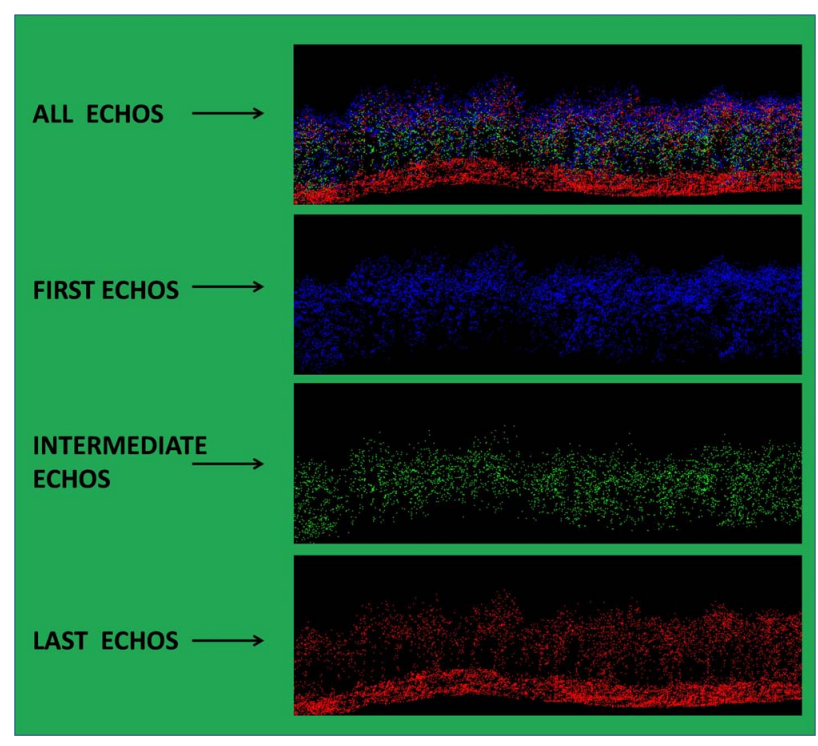

Fig. 2. Examples of multiple returns from Lidar.

points which are considered to be below the ground, whereas the second routine identifies isolated points such as points present in the air (for example birds, etc.).

The next processing step uses the Axelsson TIN model (Axelsson, 2000) in an attempt to define a "ground" surface. To accept or reject points as being representative of the "ground" is necessary to define some geometric threshold values which prescribe possible deviations from the average topographic surface. For example maximum building size of largest buildings. The algorithm looks for the so-called "key points", i.e. the lowest point that will define a first ground surface made up of very large triangles. A triangle of the primary mesh is progressively densified by adding a new vertex to a point inside it.

The "Classification of points below surface" allows the identification of points under the surface level, such as wells or similar. The latest two classifications (v and vi) identify and classify points according to a given class or heights, respectively. See as an example Fig. 2, which shows the different heights of vegetation cover Finally, the DTM was created using TerraModeler on the basis of the classification of terrain and off terrain objects performed.

\subsection{DTM data processing}

DTM was processed using spatial autocorrelation statistics which measure and analyze the degree of dependency among features that have clusters of similar or dissimilar values.

Spatial autocorrelation is generally described through some indices of covariance for a series of lag distances (or distance classes) from each point. The plot of the given indices against the distance classes is called correlogram, that illustrates autocorrelation at each lag distance. The distance at which the value of spatial autocorrelation crosses the expected value, indicates the range of the patch size or simply the spatial range of the pattern.

Classic spatial autocorrelation statistics include a spatial weights matrix that reflects the intensity of the geographic relationship between observations in a neighbourhood. Such spatial weights matrix indicate elements of computations that are to be included or excluded. In this way it is possible to define ad hoc weights to extract and emphasize specific pattern. In this study we used the statistics from Local Moran's I, Geary's C, and Getis-Ord Local Gi index (see Anselin, 1995; Getis and Ord, 1992).

The use of classic spatial autocorrelation statistics such as Moran's I, Geary's C, and Getis-Ord Local Gi index enables the characterization of the spatial autocorrelation within a user-defined distance. For each index, the output is a new image which contains a measure of autocorrelation around the given pixel. In particular:

(i) the Local Moran's I index identifies pixel clustering. Positive values imply the presence of a cluster of similar values which means low variability between neighboring pixels, whereas negative values indicate the absence of clustering which means high variability between neighboring pixels.

(ii) the Getis-Ord Gi index permits the identification of areas characterized by very high or very low values (hot spots) compared to those of neighboring pixels,

(iii) the Local Geary's C index allows us to identify edges and areas characterized by a high variability between a pixel value and its neighboring pixels.

All of these indices are available as tools of commercial software for Geographical Information System (GIS) or image processing such as ENVI.

\section{Results}

The study area is the natural park of Bosco dell' Incoronata that has an extension of around 1060 ha, with 162 ha of woodland (Quercus pubescens) and 115 ha of prairies. The study area is located $12 \mathrm{~km}$ away from Foggia (see Fig. 3) within the Tavoliere delle Puglie (Southern Italy). The investigated area is an important site from the naturalistic, historical and archaeological point of view. Bosco dell'Incoronata is an ancient lowland forest that was still present in the medieval time, and has been characterized by a long and intensive human activity probably from Neolithic to Middle Ages (Mazzei, 2003) as evident from archaeological remains and historical documentation. As regards to the medieval time, historical record attests (see for example Huillard and Bréholles 1859; Caruso, 1952) that Frederick II of Hohenstaufen (26 December 1194-13 December 1250) used to spend long periods in Foggia, which was a strategic position 


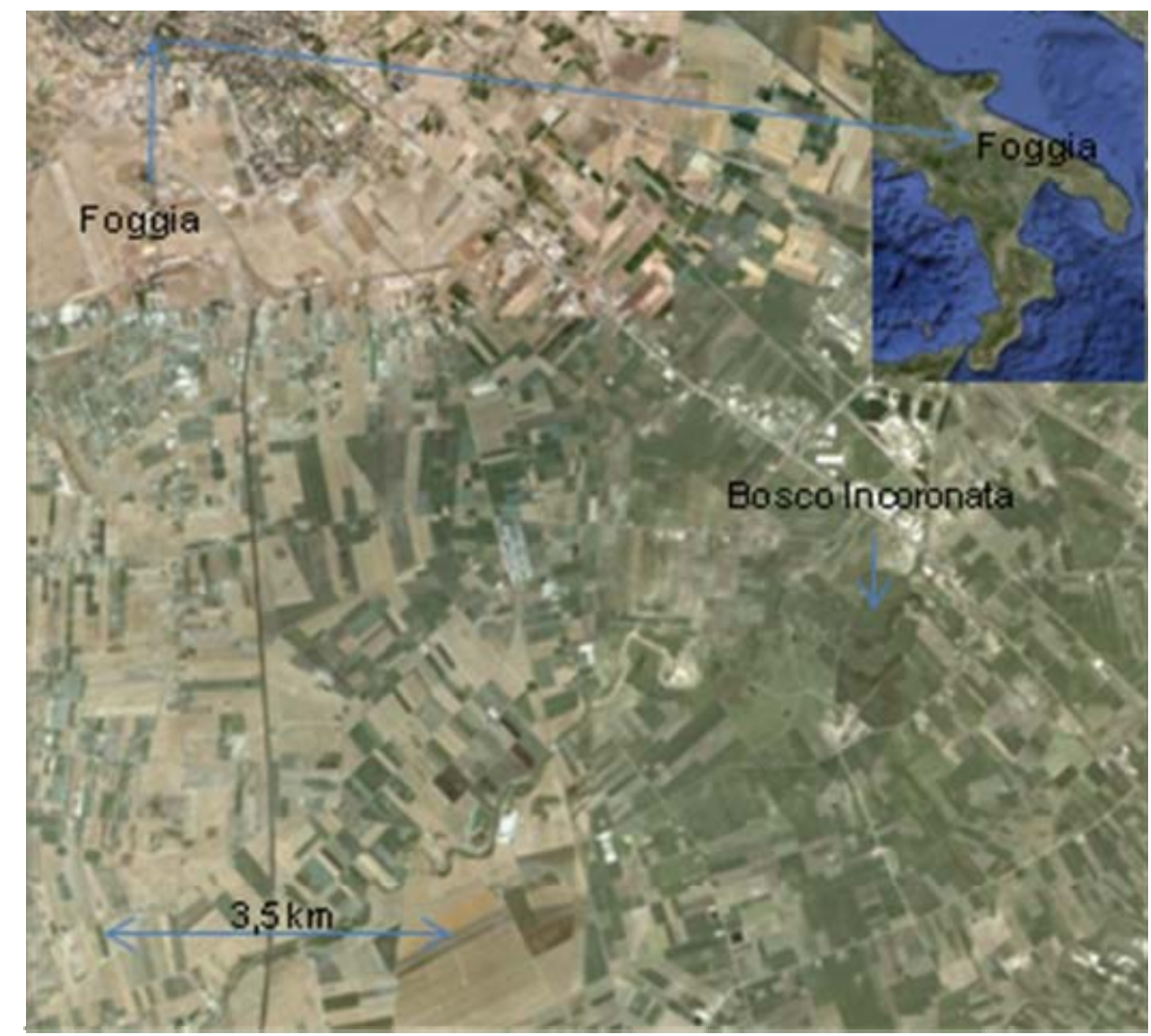

Fig. 3. Location of the study area.

to reign over a vast territory extended from German to Sicily. During the Frederick's kingdom two royal residences, the "domus pantanii S. Laurencii" (palace of S. Lorenzo lake) and the "Domus Coronate", were specifically built or restored for the imperator, both of them were located very close to Foggia.

They are mentioned in the list of castles and domus needing repairs included in Statutum de reparatione castrorum (the regulations for repairing the castles), written in 1241-46 (Sthamer, 1914).

The "domus pantanii S. Laurencii" has been widely investigated and excavated, whereas very little is still known about the domus Coronate which was probably within the "medieval" forest area of Bosco dell'Incoronata, also known as the Frederick's woodland.

In this paper, our investigations have been mainly focused on the identification of traces of ancient landscapes and paleaoenvironment features in order to improve knowledge about the transformation of the territory, which is a crucial point and an invaluable data source for performing detailed archaeological investigations.

Satellite view and DTM, extracted from LiDAR survey, of the investigated area are shown in Fig. 4. The satellite picture shows an intensive agricultural activity with arable lands ap- pearing everywhere in connection with major post-war land reforms (around 1950). This modern land use is certainly similar to the land use designed after the Second World War (during Fifties). This long and intense agricultural activity, along with the use of agricultural equipment and machinery for production, has generally destroyed traces of past landscapes. Nevertheless, subtle microtopographic relief are still preserved and visible from DTM extracted from the LiDAR survey following data processing detailed in Sect. 2. Such a DTM enable us to identify some paleaoriverbeds of the Cervaro river shown in Fig. 4 (bottom) by black arrows (1 to 3 ) along with the actual stream of the Cervaro torrential river enhanced by light blue arrows. It is quite interesting to note that the river changed many times from North to South side compared to the present stream. Traces of past human activities may be still evident close to these paleaoriverbeds and they were identified from DTM mainly in the area within the lack circles numbered from 1 to 3 . Intensive study of the ancient landscapes of this area of the Tavoliere of Foggia is only just beginning and so far questions tend to be raised rather than answered. At this stage of the investigations, it seems evident that in the circled areas, numbered 1 and 2, human settlements taken place more probably exploiting the water closeness and availability. Paleaoriverbed number 1 is 

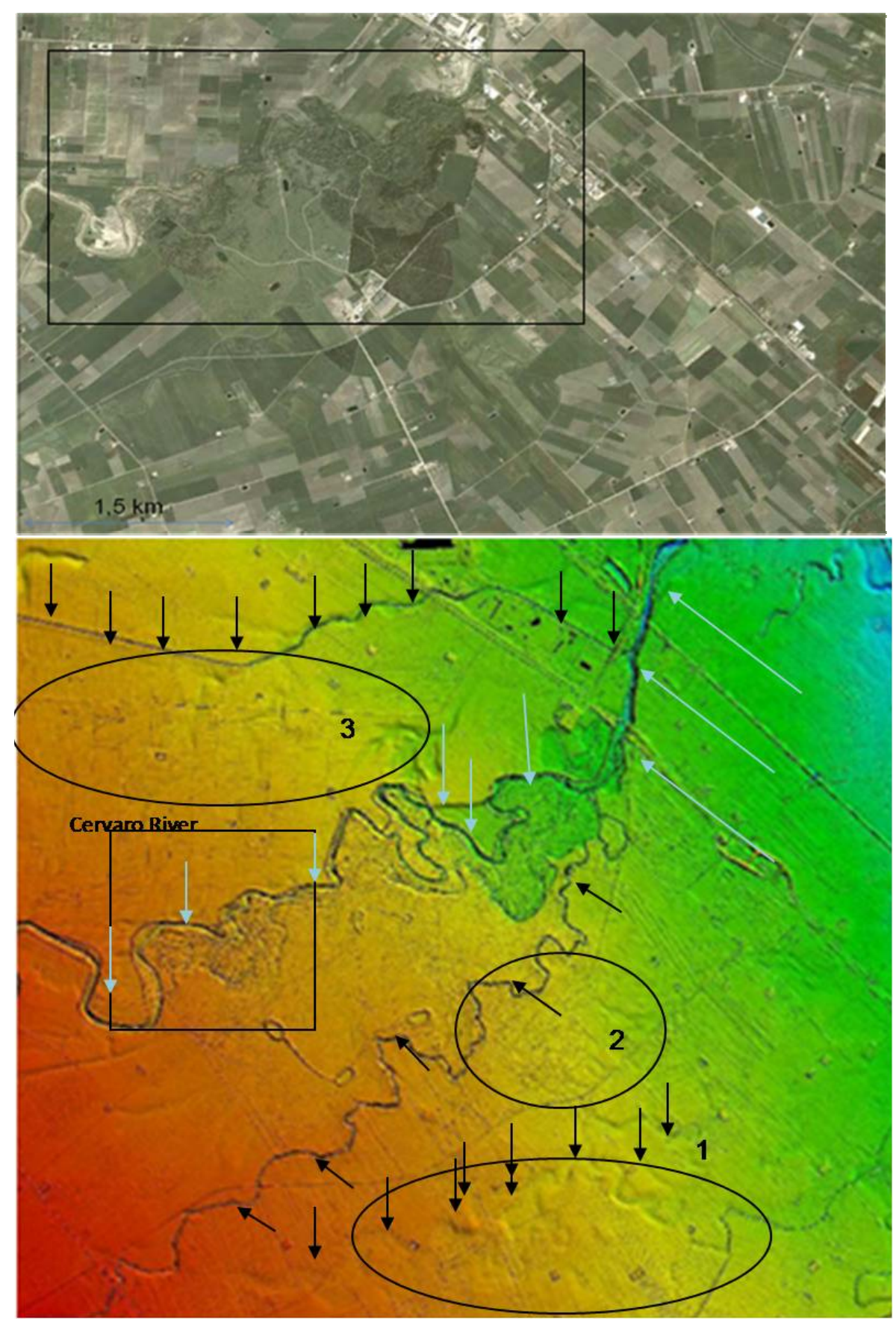

Fig. 4. (Up) ortophoto of the study area; (bottom) DTM from LiDAR, rectangle indicates the area of the mayor interest from the landscape archaeology prospective. Black arrows indicate the paleaoriver bed of the Cervaro River, brown arrows indicate the actual stream of the river. Circles indicate trace of past human activities.

less visible that those indicates as 2 and 3 and this may suggest that it is the most ancient. Inside circle number 3, there are some traces of roman centuriation which were not linked to the presence of river. Such patterns are probably related to early Roman times and suggest predominance of cultivation. Certainly by the end of the Middle Ages, the area was much more involved in a highly specialized form of commercial sheep as evident by the presence of a number of "tratturi", recently listed in the Unesco Heritage.

Figure. 5 shows results from spatial autocorrelation statistics, maps from Moran index (upper left), Geary's (upper left), Getis (lower left) and RGB of all the three indices. In 


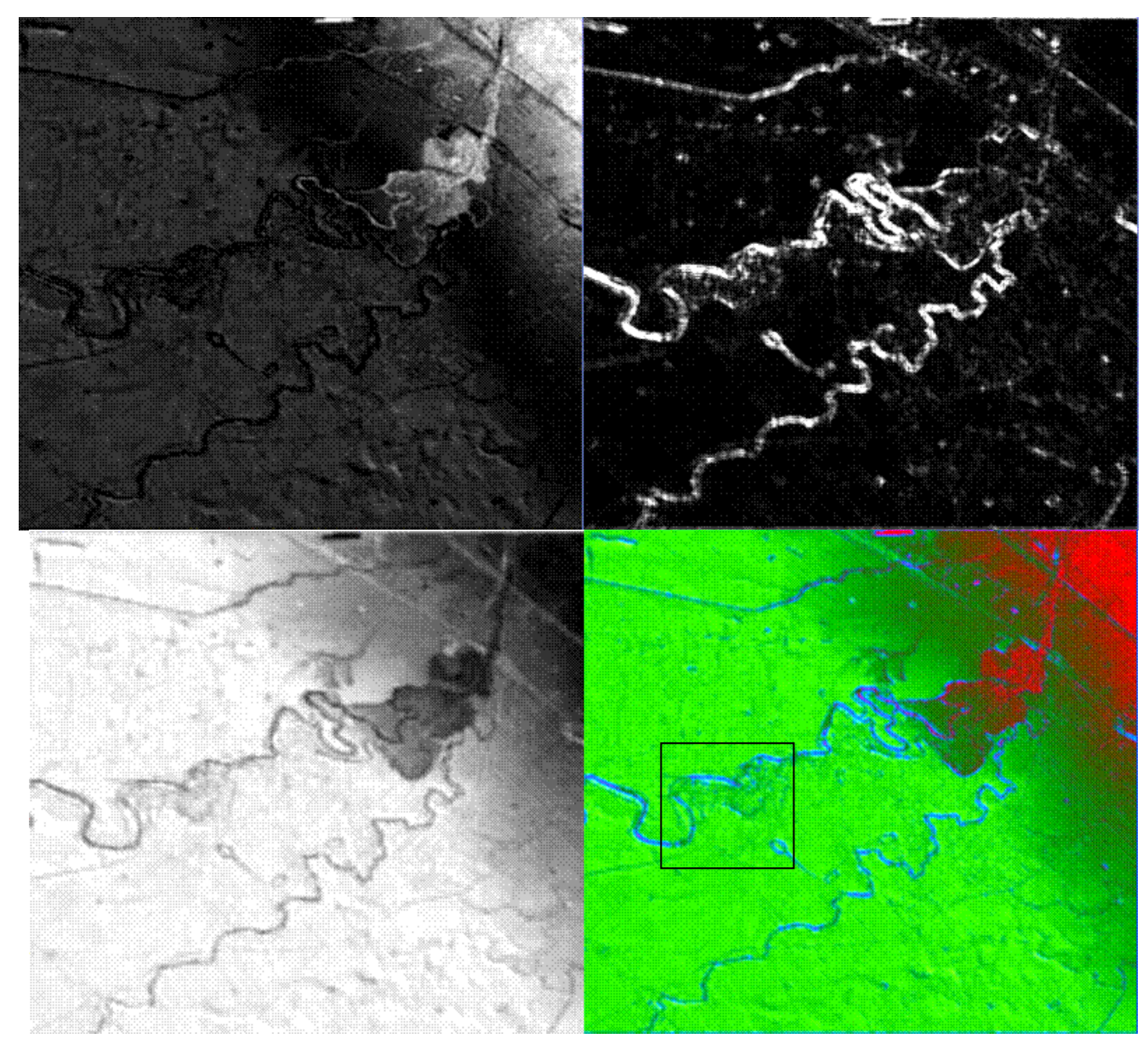

Fig. 5. Results from spatial autocorrelation statistics, maps from Moran index (upper left), Geary’s (upper left), Getis (lower left) and RGB of all the three indices (upper right).

particular, the most interesting results were obtained from the Local Geary's C index which allows us to identify edges and areas characterized by a high variability between a pixel value and its neighboring. This enabled the setting up of an automatic procedure for the recognition and the classification of the subtle traces of landscape transformations. Figure 5 (upper left) clearly identifies 3 classes and among them the blue highlighted traces of actual and ancient river streams, which are particularly important because provide us information on potential location of archaeological settlements.

Finally, black rectangle indicates the woodland area found to be of the mayor interest and therefore, analyzed in more details. Figure 6 shows LiDAR and orthophoto acquired at the same time as LiDAR data. In particular, lower left figures clearly shows the capability of LiDAR to penetrate the vegetation canopy and to identify traces of ancient features still fossilized and evident into the modern landscape and sharpened using local autocorrelation statistics (see upper right figure).

\section{Final remarks}

In this study, the investigations based on ALS survey and aerial photos were carried out for the protected area of Bosco dell'Incoronata in the Apulia Region (Southern Italy). It is an important site from the naturalistic, historic and archaeological point of view. Bosco dell'Incoronata is an ancient lowland forest that was still present in the medieval time, and has been characterized by a long and intensive human activity from Neolithic to Middle Ages, as testified by archaeological remains and historical documentation.

In this paper we focused on LiDAR-based investigations addressed to the identification of traces of ancient landscapes and paleaoenvironment features, which are invaluable data source for archaeological investigations. The detailed DTM extracted from LiDAR allowed us to identify features not visible from ground or from aerial photos (taken at the same time as LiDAR survey) because hidden by forest canopy and dense understory. The aerial photos show an intensive agricultural activity with arable lands appearing everywhere in connection with major post-war land reforms (around 


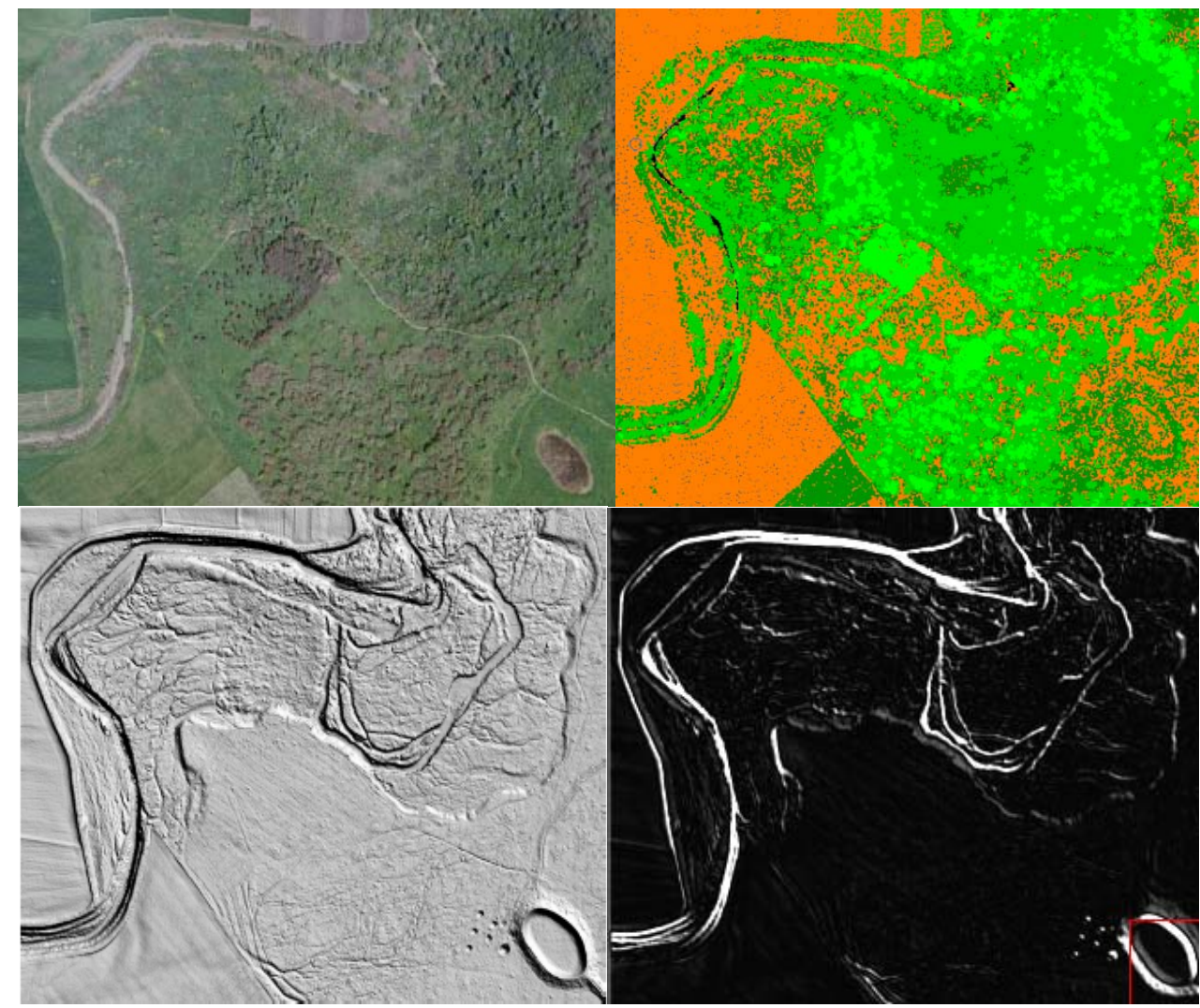

Fig. 6. (Upper left) orthophoto acquired at the same time as LiDAR data, (upper right) results from the classification of LiDAR raw data; (upper left) DTM which clearly shows the capability of LiDAR to penetrate the vegetation canopy, and (upper right) map from the spatial autocorrelation analysis Geary's index.

1950). The mechanization of agricultural activity has strong modified the whole area of the Tavoliere and has destroyed traces of past landscapes.

The DTM enabled us to identify subtle microtopographic relief linked to traces of past landscapes, as in the case of the Cervaro paleaoriverbed. It is quite interesting to note that the river changed many times from the North to the South side of the present stream. Subtle traces of past human activities are still evident close to the paleaoriverbeds. Intensive study of the ancient landscapes of the Bosco dell'Incoronata is just beginning and so far questions tend to be raised rather than answered.

Our results pointed out that the use of aerial LiDAR is strategic for archaeological and paleoenvironmetal investigations, also considering the fact that in the next future, LiDAR surveys are scheduled to have a national coverage in Italy and in a number of European countries, and data should be available at a reduced cost for research and educational purposes. The integrated use of diverse technologies in archaeology can profitable give the opportunity to take benefit from each of them to conduct research over large areas with reducing costs and no disturbance to archaeological sites.
Edited by: L. Eppelbaum, N. Masini, and F. Soldovieri Reviewed by: two anonymous referees

\section{References}

Anselin, L.: Local Indicators of Spatial Association LISA, Geogr. Anal., 27, 93-115, 1995.

Axelsson, P.: DEM generation from laser scanner data using adaptive TIN models, in: International Archives of Photogrammetry and Remote Sensing, XXXIII B4/1, 110-117, 2000.

Caruso, A.: Indagini sulla legislazione di Federico II di Svevia per il Regno di Sicilia, Le leggi promulgate a Foggia nell'aprile 1240, in: Archivio Storico Pugliese, Bari, IV, 1, 41-68, 1951.

Corns, A. and Shaw, R.: High resolution LiDAR for the recording of archaeological monuments \& landscapes, Advances in Remote Sensing for Archaeology and Cultural Heritage Management, edited by: Lasaponara, R. and Masini, N., Aracne, Roma, Italy, 99-102, 2008

Crosta, A. P., Sabine, C., and Taranik, J.V.: Hydrothermal Alteration Mapping at Bodie, California, using AVIRIS Hyperspectral Data, Remote Sens. Environ., 65, 309-319, 1998.

Crutchley, S.: Ancient and modern: Combining different remote sensing techniques to interpret historic landscapes Advances in 
Remote Sensing for Archaeology and Cultural Heritage Management, edited by: Lasaponara, R. and Masini, N., 103-106, Aracne, Roma, Italy, 2008.

Devereux, B. J., Amable, G. S., Crow, P., and Cliff, A. D: The potential of airborne lidar for detection of archaeological features under woodland canopies Antiquity, Antiquity, 79, 648-660, 2005.

Doneus, M., Briese, C., Fera, C. M., and Janner, M.: Archaeological prospection of forested areas using full-waveform airborne laser scanning, J. Archaeol. Sci., 35, 4, 882-893, 2008.

Favia, P., Annese, C., De Venuto G., and Romano A. V.: Insediamenti e microsistemi territoriali nel Tavoliere di Puglia in età romana e medievale: l'indagine archeologica del 2006 nei siti di San Lorenzo "in Carminiano" e di Masseria Pantano in Armando Gravina (a cura di), Atti del $27^{\circ}$ Convegno Nazionale sulla Preistoria-Protostoria-Storia della Daunia, San Severo 2526 Novembre 2006, 91-121, Italy, 2007.

Getis, A. and Ord, J. K.: The analysis of spatial association by use of distance statistics, Geogr. Anal., 24, 189-206, 1992.

Giardino, M.: NASA activities in the field of Remote sensing of archaeology in Advances in Remote Sensing for Archaeology and Cultural Heritage Management, edited by: Lasaponara, R. and Masini, N., Aracne, Roma, Italy, 103-106, 2008.

Huillard, J. and Bréholles, L. A.: Historia diplomatica Friderici secundi, a cura di J. L. A. Huillard-Bréholles, V, 2, Parisiis, 793798, 1859.

Kruse, F. A., Boardman, J. W., Lefkoff, A. B., Heidebrecht, K. B., Shapiro, A. T., Barloon, P. J., and Goetz, A. F. H.: The Spectral Image Processing System (SIPS) - Interactive Visualization and Analysis of Imaging Spectrometer Data, Remote Sensing of Environment, 44, 145-163,1993.

Lasaponara, R. and Masini, N.: QuickBird-based analysis for the spatial characterization of archaeological sites: Case study of the Monte Serico medieval village, Geophys. Res. Lett., 32, L12313, doi:10.1029/2005GL022445, 2005.
Lasaponara, R. and Masini, N.: On the potential of Quickbird data for archaeological prospection, Int. J. Remote Sens., 27, 15-16, 3607-3614, 2006.

Lasaponara, R. and Masini, N.: Detection of archaeological crop marks by using satellite QuickBird multispectral imagery, J. Archaeol. Sci., 34, 214-221, 2007.

Lasaponara, R. and Masini, N.: Editorial of the Special Issue of Journal of Cultural Heritage "Remote Sensing for Cultural Heritage Management and Documentation", J. Cult. Herit., 10 , 1$2, ., 2009$.

Lasaponara, R. and Masini, N.: Full-waveform Airborne Laser Scanning for the detection of medieval archaeological microtopographic relief, J. Cult. Herit., 10, 78-82, 2009.

Lasaponara, R., Coluzzi, R., Gizzi, F., and Masini, N.: On the LiDAR contribution for the archaeological and geomorphological study of a deserted medieval village in Southern Italy, J. Geophys. Eng., 7, 1-9, 2010.

Luzzato, G.: An economic History of Italy: From the fall of the Roma Empire to the XVI century First Published in 1961, reprinted in 2006 by Toutledge 2 Park Square, of Taylor and Francis group medieval, London, 2006.

Mazzei, M.: Levate aeree per la conoscenza e la gestione del territorio in Lo sguardo di Icaro a cura di Marcello Guaitoli, 115, 8888168125 , detail can be found at: http://openlibrary.org/b/ OL19515586M/sguardo_di_Icaro, 2003.

Sthamer, E.: Die Verwaltung der Kastelle im Königreich Sizilien unter Kaiser Friedrich II und Karl I von Anjou, Leipzig, Germany, p. 58, 1914. 